\title{
Big Data Analysis, Use of Facebook Data.
}

\author{
Irida Gjermeni ${ }^{1 *}$ Dudina Hoxha ${ }^{2}$ \\ 1. Department of Mathematic and Informatics, Agricultural University of Tirana, "Pajsi Vodica" St., 1029 \\ Tirana, Albania \\ 2. School of Business Informatics, Agricultural University of Tirana, "Pajsi Vodica" St., 1029 Tirana, \\ Albania \\ * E-mail of the corresponding author: igjermeni@ubt.edu.al
}

\begin{abstract}
$90 \%$ of disponible data are created in recent years. Big Data term was know for the first time since 2005, and even before in Mesopotamia, in order to register the increased of their productions. But evolution erea of Big Data started at 20 century. Early data are from 1887, when Herman Hollerith created a computer that read wholes made on a card to organize registered data. Every our device is connected with internet of things (IoT), from which we can use and collect data. Collected data can help business understanding consumer model and behaviors. But big data is more than that. Big Data can help schientifics to face global problems, and business to face the right decision.

The best example how big data had changed our live are social media. Use of big data collected from social media network help business to understand consummator behavior, audience groups and their dedication on studied situation. Our research focused in building an analysis informatic model, to analyse data collected from facebook pages.
\end{abstract}

Keyword: IoT(Internet of things),Big Data,Social Media.

DOI: $10.7176 / \mathrm{CTI} / 8-01$

\section{Introduction}

Social platforms like Twiter,Instagram and Facebook, are the main enivroment for politic, product, idea, notification marketing. More websites integrates user social profiles in their recomandation system.

Big data is not only e technology, but a combination of technology old and new one, that help today companies to gather important and useful information. Big Data is an ability to manage a large volume of diffent type of data. Characterists of big data are listened below:

1. Volume: quanty of data

2. Velocity: how rapidly is the process of data

3. Diversity: Different type of data

4. Correclty: How correct are those data

5. Value: how valuable are those data.

The main idea of this reseach was to offer large inovative business a fast way to analyse in real time, a large amount of data, collected from social media. Collected data will be used from business to answer question like where and what to do.

Figure 1 ilustrate cycle of big data management. After fulfillement of this phase, data are avalaible for analysis depend of addressed problem. After that business management is able to make a decision depend on the analysis result. 


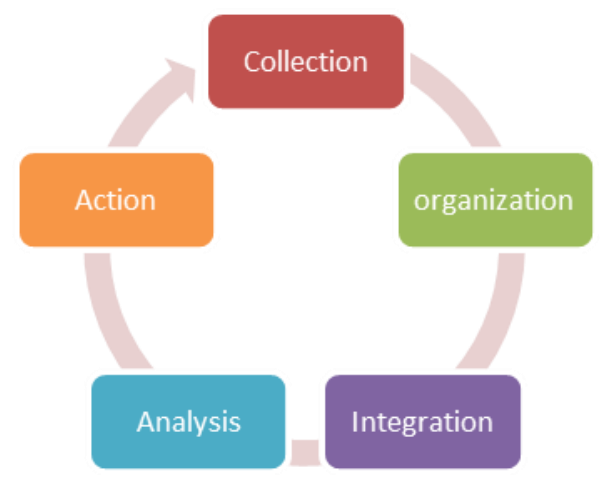

Figure 1 Cycle of big data management.

Architecture of data management, must involve a variety of services, that create opportunities for company to use efficienty and faster data. Figure 2 ilustrate basic level of architecture.

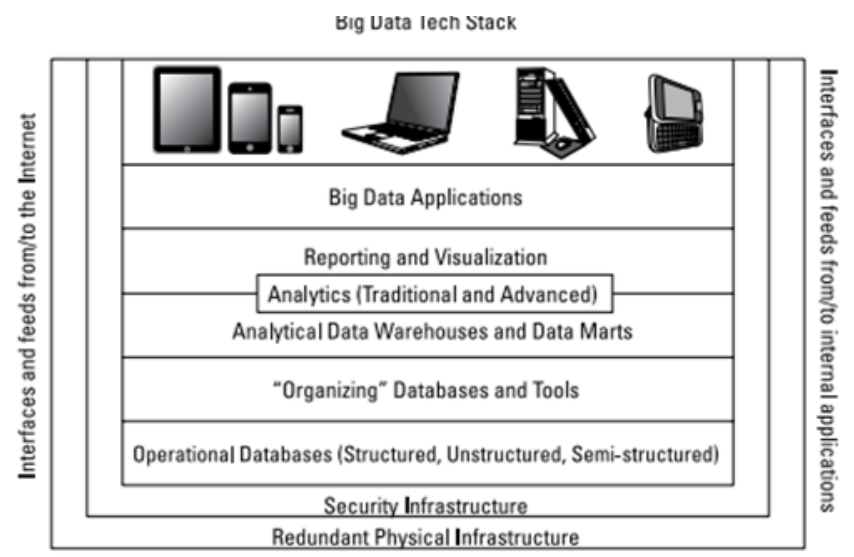

Figure 2: Architecture of big data.

Importance of big data is not how large is the company but how this company use collected data. Bussiness must collect data from diferent source and analyse them for a reason like:

- Cost reduction: Use of Hadoop present cost reduction for business. Hadoop help business in identification of effective methods to do business. Below is a scheme of Hadoop architecture and use

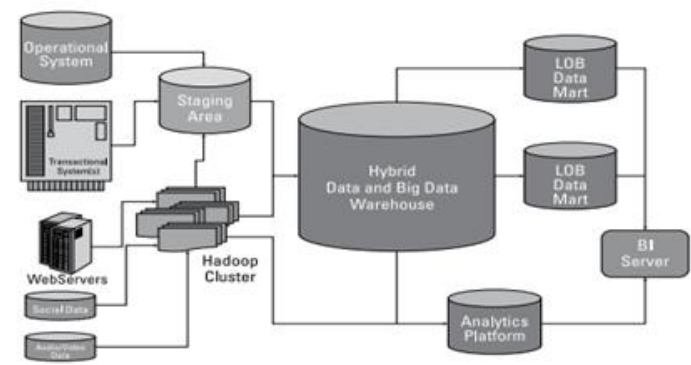

Figure 3: Hadoop Architecture.

- Time reduction: Use of big data resources help business management analyse in real time and make e decision faster in base of gained knowledge.

- Development of new product: By knowing trends of customer needs and desires, bussines are ables to create new innovative and successful products.

- Understand trade conditions: By analysis data, business management can understand more deeper trande condition. For example, analyzing customer behavior, a company can understand which is the product 
best seller in order to produce more of this product.

- $\quad$ Check online reputation: If company use big data method, management was able monitoring their online presence and improve a best presence

One of the greatest improvement of today bussines is to predict changes in the future to success. Companies desires to applied gained knowledge from big data to improve increasements on bussines revenue. Planification process througt big data passes on four phases:

- $\quad$ Planning

- $\quad$ Analysis

- Data control

- Decision made

Phase 1: Data Planning

For business managers to mae e good decision, it's important to understand connetion between data. In many cases managers does'nt have enough data when make a decision. If bussineses need to enlarge their activities, they must take in consideration data from diferent resources and directions, in order to made a deeper analysis about what they want. Planning process requires a variety of data in order to test diferent bussines assumptions and ideas.

Phase 2: Analysis

After than business management have understand the main organization aim, must analyzing data. Data analysis should traducet to bussines knowledge.

Phase 3: Data control

During the process of data analysis must be made a control to check if this analysis have inpact on bussines needs, if collected data are consistent. In this phase companies will be sure that data sources will not sent them in wrong direction.

Phase 4: Decision made

After analysis process, managers can perform an action plan. Any time that process create a new bussines strategy, it's important to use a evaluation cycle for data. The bussines Succes key is to make a decision depend on big data analysis result and test if this decision match a sucesful bussines strategy.

\section{Methods}

The application is designed in Visual Studio 2017 and database in SQL Management Studio 2012. Technology used is ASP.net Core MVC.

Application start with login page. Only loged users can view informations.After success log-in, interfaces shown as below.

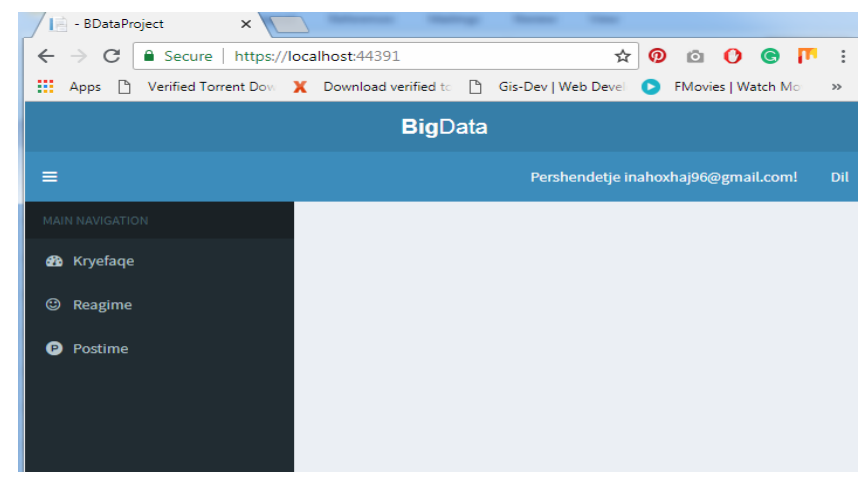

Figure 1 User Interfaces

Interface is very easy to use. If you click on "Reagimet" link, you will seen profiles of people more liked, active, dissatisfied on facebook as below figure. Information also may filtered by data (top 9 facebook user profile). 


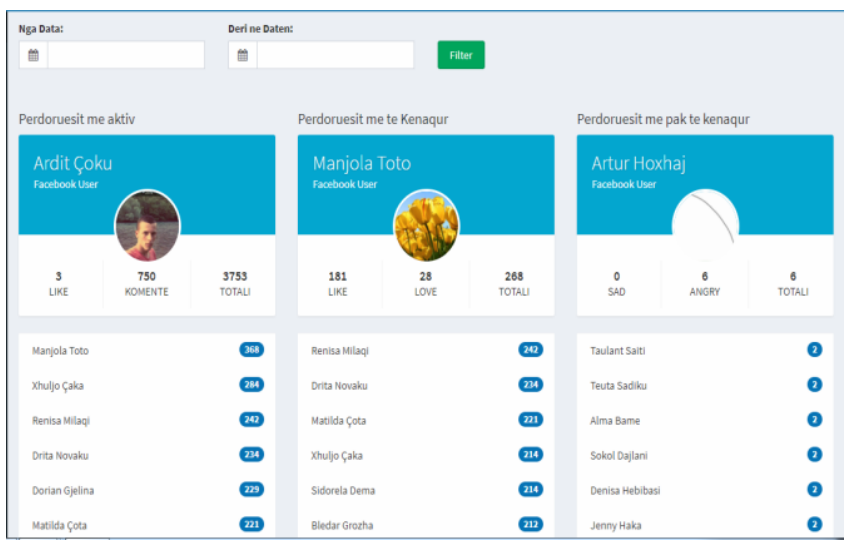

Figure 1 Top satisfied FaceBook User Profile

If the user click on "Postime" Link will shown 10 posts with most comment and reactions. Interface show data filtered by date. See Figure Below.

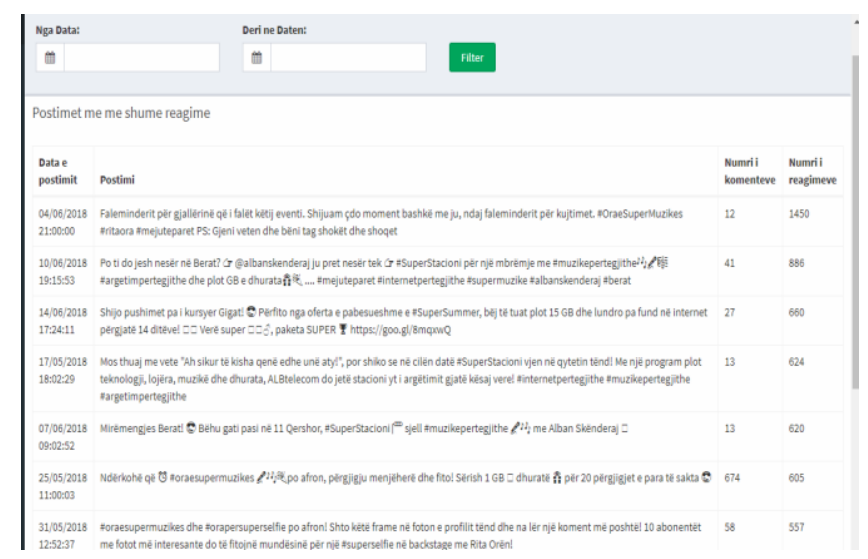

Figure 3 User Interfaces Comments

The data that are used in our test application, are collected from ALBtelecom Albania FaceBook page. Application take from FaceBook Page user reaction, user name and surname, posts leaved on this page. For this we have created e reaction Model like this below:

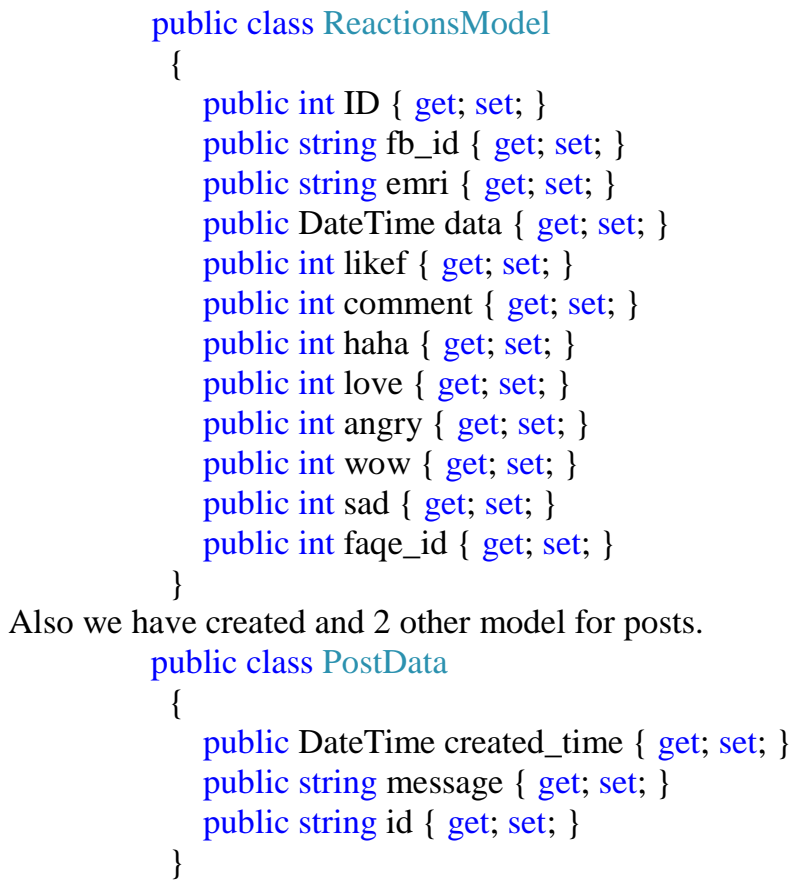

Also we have created and 2 other model for posts.

public class PostData

\{

public DateTime created_time \{ get; set; \}

public string message \{ get; set; \}

public string id \{ get; set; \} 


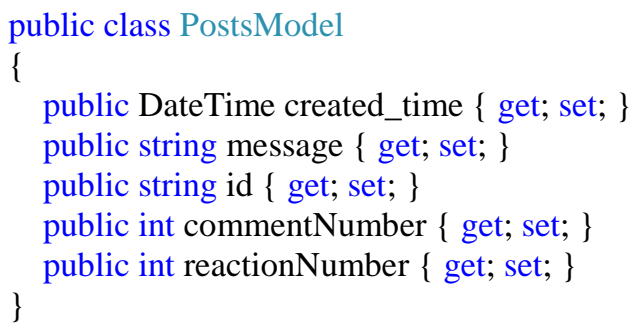

For connect our application with FaceBook Data we have created the code below: string url =

"https://graph.facebook.com/379084925464553?fields=posts\&limit=500\&access_token=1300406886674650|Q6 oKO-iXz0TFGMklDkBE08f7B8Y";

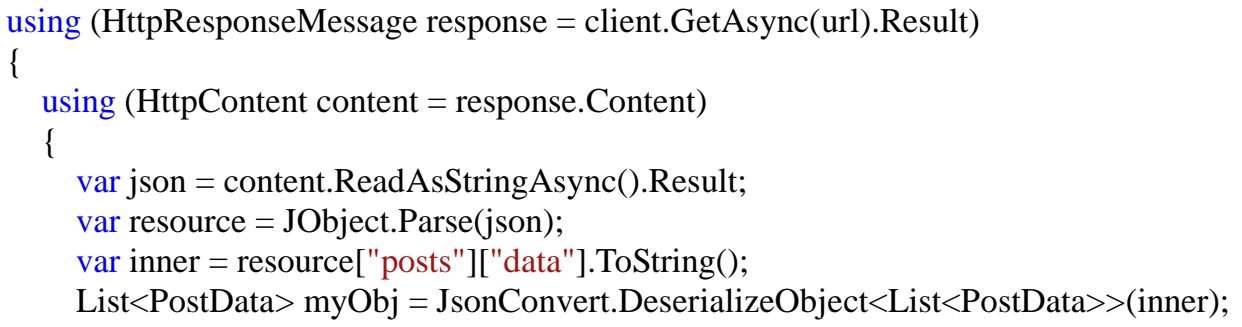

All the activities are real time. Accessing this reaction we have created controller.

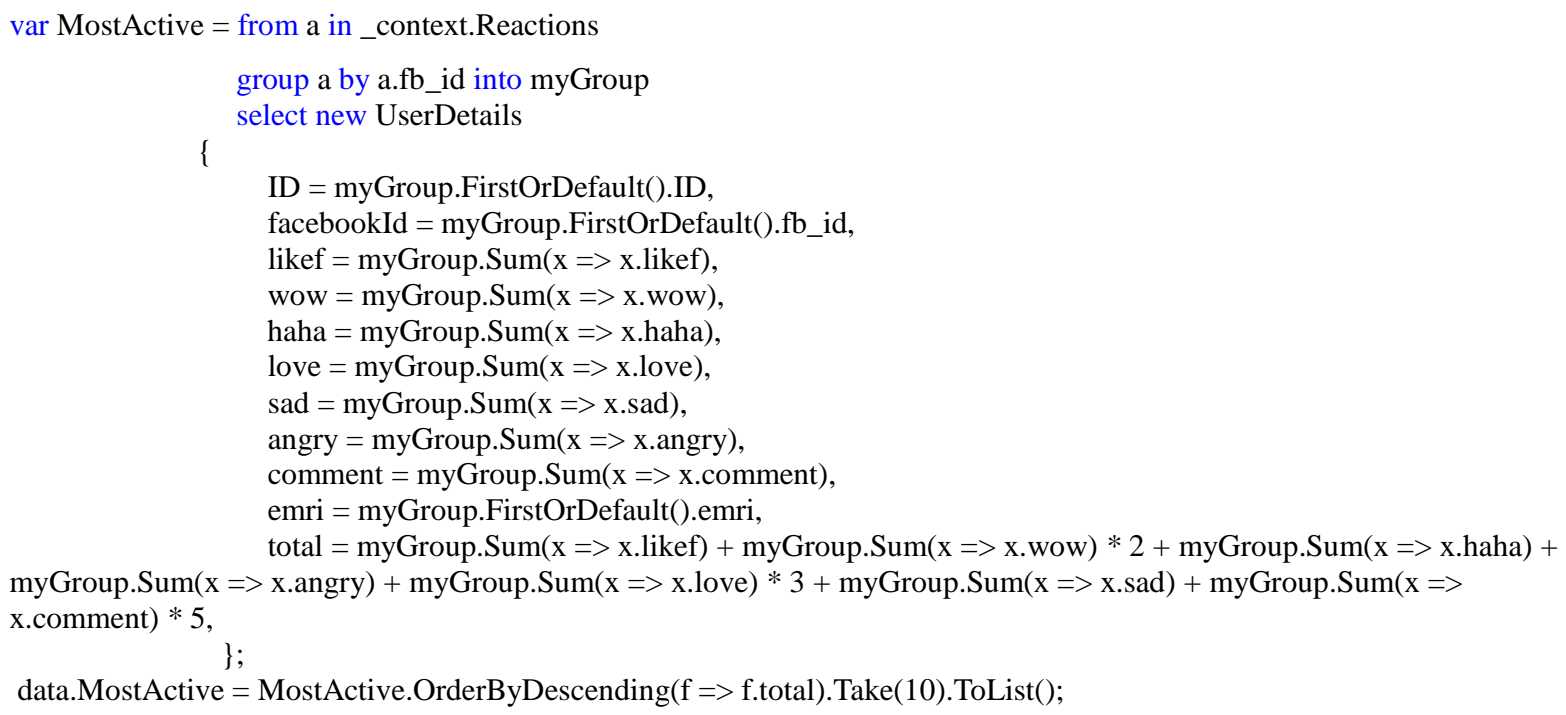

Also we can filter data for reactions and posts.

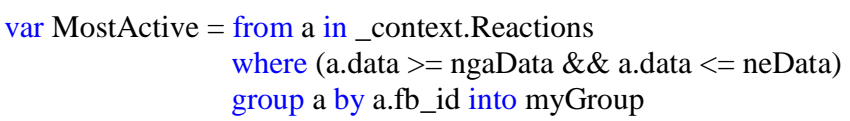

Each of reactions, posts and comments has their own view In format as below $<$ h4 $>$ Perdoruesit me aktiv $</ \mathrm{h} 4>$

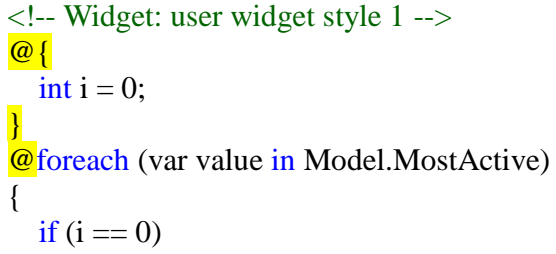




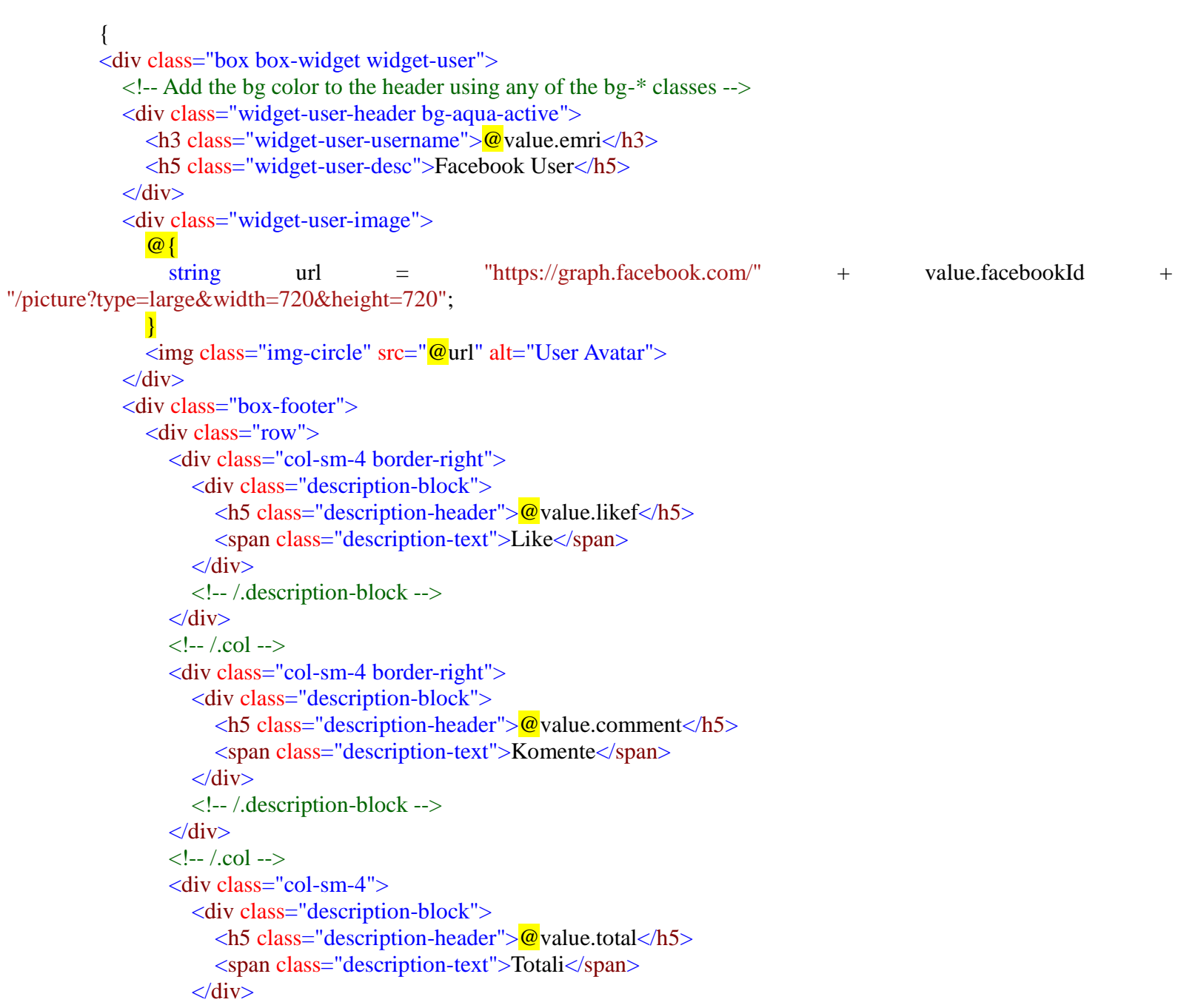

\section{Conclusions}

One bussines can fail if the bussines process is not well designed and efficient. This bussines consume more for works that are easy to do. In such cases resourses are not well used. Many company spend $20 \%$ to $30 \%$ of their revenue inefficiently every year.

Bennefits of using big data are:

- $\quad$ Corect definition of what to measure.

- $\quad$ Ecxact Measurement of what will happen in any phase of bussines process.

- Data analysis and judge base of result.

- Use of analysis on process enhancement.

- $\quad$ Commitment of improvement and measure again.

- Use of an notification system for any failure process.

\section{References}

Oracle "Mastering Big Data: CFO Strategies to Transform Insight into Opportunity", Dhjetor 2012:

http://www.fsn.co.uk/channel_bi_bpm_cpm/mastering_big_data_cfo_strategies_to_transform_insight_into_oppo rtunity\#.UO2Ac-TTuys

MartinHilbert.net. 13 Prill 2016. "The World's Technological Capacity to Store, Communicate, and Compute Information" http://www.martinhilbert.net/WorldInfoCapacity.html/

Marr, Bernard (6 Mars 2014). "Big Data: The 5 Vs Everyone Must Know"

https://www.linkedin.com/pulse/20140306073407-64875646-big-data-the-5-vs-everyone-must-know/ 
Magoulas, Roger; Lorica, Ben (Shkurt 2009). "Introduction to Big Data". Versioni 2.0. Sebastopol CA: O'Reilly Media (11). https://www.oreilly.com/data/free/release-2-issue-11.csp

Big Data Solution Offering". MIKE2.0. 8 Dhjetor 2013.

http://mike2.openmethodology.org/wiki/Big_Data_Solution_Offering

"Big Data Definition". MIKE2.0. 9 Mars 2013. http://mike2.openmethodology.org/wiki/Big_Data_Definition https://www.forbes.com/sites/bernardmarr/2015/09/08/4-ways-big-data-will-change-everybusiness/\#4bb297242729 Bernard Marr 8 Shtator, 2015 